\title{
Late Ovarian and Intestinal Extramedullary Relapse of Acute Myeloid Leukemia with Inv 16 after Allogeneic Hematopoietic Stem Cell Transplantation
}

\begin{abstract}
Mensah-Glanowska P1*, Glanowski D², SporekKunicka A ${ }^{1}$, Kviatkouskaya $\mathbf{K}^{1}$, Szostek $\mathbf{M}^{1}$, Piątkowska-Jakubas $\mathbf{B}^{1}$ and Skotnicki $\mathbf{A B}^{1}$ ${ }^{1}$ Department of Haematology, University Hospital in Krakow, J agiellonian University Collegium Medicum, Krakow, Poland

${ }^{2}$ Departments of Obstetrics and Gynecology with Oncology, Gabriel Narutowicz Specialized Municipal Hospital in Krakow, Krakow, Poland

*Corresponding author: Mensah-Glanowska P, Department of Hematology, University Hospital in Krakow, J agiellonian University Collegium Medicum, Krakow, Poland
\end{abstract}

Received: March 29, 2018; Accepted: April 25, 2018; Published: May 02, 2018

\begin{abstract}
Treatment of Acute Myeloid Leukemia (AML) Extramedullary Relapse (EMR) after Allogenic Hematopoietic Stem Cell Transplantation (allo HSCT) is challenging. EMR pathogenesis of this entity is not clearly elucidated. Variety of factors affects clinical approaches in diagnostics, treatment and prognosis. Furthermore, there is no current consensus for post-transplant AML EMR treatment. We present here the case of young AML female patient with rare EMR presentation: ovary and large intestine infiltration. The treatment combined different strategies -conservative like surgery and chemotherapy, but also effective new approaches of targeted therapy - hypomethylating agent with tyrosine kinase inhibitor.
\end{abstract}

Keywords: Extramedullary Relapse; AML: Acute Myeloid Leukemia; Allo HSCT: Allogenic Hematopoietic Stem Cell Transplantation; PET/CT: Positron Emission Tomography

\section{Abbreviations}

AML: Acute Myeloid Leukemia; BAL: Bronchoalveolar Lavage; CBF: Core Binding Factor; FAM: Fluticasone/Azitromycine/ Montelukast; FDG: Fluorodeoxyglucose; HRCT: High Resolution Computed Tomography; MIP: Maximum Intensity Projection; MRD: Minimal Residual Disease; PET/CT: Positron Emission Tomography/Computed Tomography; SIRS: Systemic Inflammatory Response Syndrome; Suvmax: Maximal Standardized Uptake Value; TK: Tyrosine Kinase

\section{Case Presentation}

23-year-old female patient was diagnosed with Acute Myeloid Leukemia (AML) inv16 (CBF-MYH11) with c-KIT mutation in July 2011. The patient underwent induction chemotherapy according to the DAC-7 protocol (Daunorubicin $60 \mathrm{mg} / \mathrm{m}^{\wedge} 2 /$ day i.v., days 1-3; Cytarabine $200 \mathrm{mg} / \mathrm{m}^{\wedge} 2 /$ day, days $1-7$; Cladribine $5 \mathrm{mg} / \mathrm{m}^{\wedge} 2 /$ day, days 1-5) and complete hematological remission was achieved. Consolidation consisted of 2 cycles with high dose Cytarabine (HAM: Cytarabine $1.5 \mathrm{~g} / \mathrm{m}^{\wedge} 2 /$ day i.v. D: $1-3$; Mitoxantrone $10 \mathrm{mg} / \mathrm{m} 2 \mathrm{D}$ : $3-5$ in September 2011 and HD-Ara-C: Cytarabine $2 \mathrm{~g} / \mathrm{m}^{\wedge} 2$ i.v. D 1, 3, 5 in October 2011). Aplasia period, after second consolidation, was complicated by severe diarrhea with Clostridium difficile etiology. Molecular MRD was positive after induction and consolidation and the patient was qualified for matched related donor allogeneic hematopoietic stem cell transplantation (MRD allo HSCT). In January 2013, the patient was admitted to transplant unit and subjected to 10/10 MRD peripheral blood stem cells transplantation with reduced toxicity conditioning according to BuClo regimen (Busilvex 3,2mg/ $\mathrm{kg} /$ day i.v. D-5 to -2 and Clofarabine $30 \mathrm{mg} / \mathrm{m}^{\wedge} 2 /$ day i.v. D-6 to -2). Hematological recovery was achieved (WBC $>1,5 \times 10^{\wedge} 9 / 1$ on $\mathrm{D}+18, \mathrm{ANC}>0.5 \times 10^{\wedge} 9 / 1$ on $\mathrm{D}+18, \mathrm{PLT}>20 \times 10^{\wedge} 9 / 1$ on $\mathrm{D}+10$, PLT
$>50 \times 10^{\wedge} 9 / 1$ on $\left.\mathrm{D}+10\right)$. First chimerism analysis revealed complete donor chimerism, but molecular Minimal Residual Disease (MRD) signal - CBF-MYH11 was positive. Because of high risk of relapse immunosuppression was tapered and finally discontinued on D+120. In September 2012, 6 months after transplant, the patient developed dry cough and dyspnoea at exertion. Spirometry revealed severe obturation, there were no abnormalities in HRCT assessment. Bronchiolitis obliterates syndrome was diagnosed and the patient restarted systemic immunosuppression (Tacrolimus+steroids) collaterally with FAM (inhaled Fluticasone/Azithromycin/ Montelukast) and Posaconazole prophylaxis with good response. In March 2013 after respiratory tract infection the patient complained of prolonged productive cough and malaise. HRCT results and microbiological BAL culture (Aspergillus fumigatus) confirmed invasive pulmonary aspergillosis. Voriconazole treatment led to resolution of symptoms and typical abnormalities in imaging. In regular control of the asymptomatic patient in September 2015, 44 months after transplantation, molecular analysis revealed positive CBF-MYH 11. With no abnormalities found both in CBC and bone marrow assessment, Positron Emission Tomography (PET/CT) was performed and presented increased FDG metabolism in the region of left ovary. Surgically removed left ovary was enlarged 50x70 mm, hard, motionless with ovarian cavity and lateral wall of the uterus. In histopathology, ovary was massively infiltrated by atypical cells with morphology of blasts. In subsequent peripheral blood MRD molecular analysis was still positive and PET/CT revealed increased FDG metabolism in the left side of lower intestine. The patient was subjected to colonoscopy with biopsy. There was no pathology on inspection and in histopathology nonspecific scanty lymphoid infiltrates were found. 2-month later, next PET/CT was performed and metabolically active areas of the descending colon $52 \times 44 \times 47 \mathrm{~mm}$, SUVmax 7,2; on the border of descending colon and distal segment
Austin J Obstet Gynecol - Volume 5 Issue 5 - 2018

Submit your Manuscript | www.austinpublishinggroup.com

Mensah-Glanowska et al. @ All rights are reserved
Citation: Mensah-Glanowska P, Glanowski D, Sporek-Kunicka A, Kviatkouskaya K, Szostek M, PiątkowskaJakubas B, et al. Late Ovarian and Intestinal Extramedullary Relapse of Acute Myeloid Leukemia with Inv 16 after Allogeneic Hematopoietic Stem Cell Transplantation. Austin J Obstet Gynecol. 2018; 5(5): 1111. 


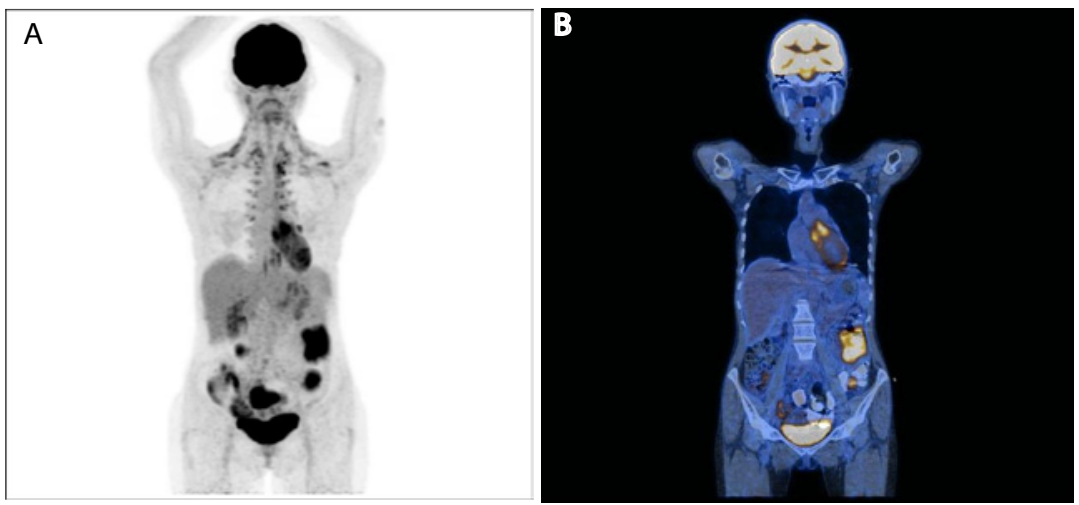

Figure 1: Extramedullary leukemia relapse PET/CT images MIP (A) and fusion (B) indicate multiple sites of FDG uptake, including descending colon, the border of descending colon and distal segment and intestinal loops, right from the rectum.

$29 \times 32 \times 36 \mathrm{~mm}$ SUVmax 6.2 and intestinal loops, right from the rectum 55x53x46mm SUVmax8,8 were noted (Figure 1A, 1B). Second colonoscopy confirmed diagnosis of extramedullary AML relapse in large intestine. To minimize the risk of severe bleeding and perforation, therapy was started with Dasatinib $100 \mathrm{mg} /$ day orally with 5 -Azacytidine $75 \mathrm{mg} / \mathrm{m}^{\wedge} 2$ for 7 days used off-label followed by systemic chemotherapy: Cytarabine $200 \mathrm{mg} / \mathrm{m}^{\wedge} 2 /$ day $(1-5)+$ Idarubicine $12 \mathrm{mg} / \mathrm{m}^{\wedge} 2 /$ day $(1-3)$ and $90 \%$-regression of infiltrate was achieved, confirmed by PET/CT with negative molecular MRD. Double induction was planned, and the patient was subjected to $2^{\text {nd }}$ course - Cytarabine $200 \mathrm{mg} / \mathrm{m}^{\wedge} 2 /$ day $(1-5)+$ Idarubicine $12 \mathrm{mg} /$ day (1-2). During aplasia, the patient developed fatal septic shock with Pseudomonas aeruginosa etiology and SIRS (Systemic Inflammatory Response Syndrome) and died in September 2016.

\section{Discussion}

Acute Myeloid Leukemia (AML) with the pericentric inversion of chromosome 16 [inv (16) (p13.1q22)] is recognized by the World Health Organization classification as unique entities within the category "AML with recurrent genetic abnormalities [1,2]. Among adults with de novo AML, inv (16) is in $5-8 \%$ of the patients [3]. Both the $t(8 ; 21)$ and inv(16) aberration result in formation of novel chimeric fusions involving genes of the Core-Binding Factor (CBF) complex, a master regulator of definitive hematopoiesis providing the common designation CBF-AML [4,5]. Compared with other cytogenetic AML groups, patients with CBF-AML are considered a favorable AML risk group based on their high remission rate and survival probabilities. However, approximately $50 \%$ of patients with CBF-AML are not cured. Full-length RUNX1-RUNX1T1 and CBFBMYH11 fusions are considered as preleukemic conditions in CBF leukemogenesis, but they alone are not sufficient to induce leukemic transformation. The acquisition of additional genetic hits is necessary for the development of a leukemic phenotype [4,5]. More than $90 \%$ of AML with inv (16) harbor additional secondary mutations affecting c-KIT, FLT3, NRAS, and KRAS [6]. I was found that c-KIT mutation adversely affected the relapse rate $[7,8]$. According to the current NCCN guidelines, AML with t (8;21) or inv (16) and mutated KIT are considered as intermediate-risk AML, not favorable-risk AML [9]. Allo HSCT is increasingly used as a potentially curative treatment for Acute Myeloid Leukemia (AML). However, relapse remains an important cause of treatment failure with relapse rates ranging from
$30 \%$ to $70 \%$ [10-12]. Extramedullary relapses are known to occur, either as isolated sites or in combination with marrow relapse [1317]. The incidence of leukemia Extramedullary Relapse (EMR) is difficult to determine. Based on retrospective data presented in the published case series and small sample studies, it is estimated at $5-12 \%$ [15,18-23]. A literature review of 112 published cases of AML extramedullary relapse finds a median onset time of 17 months (range 1-121) post-transplant, with sites reported (in order of highest frequency) in skin, breast, bone, testis, serosa, gynecological tract, and bladder [15]. The potential mechanism of the development of EMR without coexisting leukemic marrow involvement is that the GraftVersus-Leukemia (GVL) effect is more potent in the marrow and may be weaker in the extramedullary sites. Donor Lymphocyte Infusion (DLI), which may augment, potentiate the GVL effect and finally eradicate marrow remnants of leukemic cells and at the same time might not be as effective in extramedullary leukemic tumor cells [24]. GVL effect derived from chronic Graft Versus Host Disease (GVHD) prevents marrow relapse and does not prevent EMR. Furthermore, previous extensive chronic GVHD has been frequently observed in patients developing EMR [25]. EMR following allo HSCT has a dismal prognosis and management in the post-transplant setting is extremely difficult $[17,18]$. Systemic chemotherapy, in addition to EMR involved areas localized irradiation, has been administered to prevent overt leukemia recurrence. However, patients who develop EMR have been previously treated with high-dose chemotherapy, radiotherapy, GVHD related immunosuppression and their risk of further treatment toxicity is very high [17].

The prognostic significance of c-KIT mutations in CBF AML is important not only for outcome prediction, but also for therapeutic implications. It has been shown that, like other mutations of Tyrosine Kinase (TK) genes in leukemia - BCR-ABL and FLT3 internal tandem duplication, gain-of-function KIT mutations may also serve as a target for TK inhibitors. The case, described above, was unusual presentation of late extramedullary CBF-leukemia relapse after allo HSCT with concomitant left ovary and left side large intestine infiltration of surrounding structures, spreading locally. Both molecular MRD and PET/CT imaging were sensitive EMR diagnostic tools. The patient was treated with surgery and chemotherapy but also with new strategies: TK inhibitor with hypomethylating agent to reduce disease burden with effective regression. Systemic chemotherapy, improves treatment efficacy. However, possibility of severe complications 
in patients with EMR after allo HSCT is extremely high. In parallel with EMR, presence of active GVHD in majority of patients creates unique immunological conditions, that predispose these patients to the development of both - subsequent EMR in diverse localizations and life-threatening complications related to chemotherapy.

\section{References}

1. Swerdlow SH, Campo E, Harris NL, Jaffe ES, Pileri S, Stein H, et al WHO Classification of Tumours of Haematopoietic and Lymphoid Tissue. International Agency for Research on Cancer. 2008.

2. Arber DA, Orazi A, Hasserjian R, Thiele J, Borowitz MJ, Le Beau MM, et al. The 2016 revision to the World Health Organization classification of myeloid neoplasms and acute leukemia. Blood. 2016; 127: 2391-2405.

3. Byrd JC, Mrózek K, Dodge RK, Carroll AJ, Edwards CG, Arthur DC, et al. Pretreatment cytogenetic abnormalities are predictive of induction success, cumulative incidence of relapse, and overall survival in adult patients with de novo acute myeloid leukemia: Results from Cancer and Leukemia Group B (CALGB 8461). Blood. 2002; 100: 4325-4336.

4. Castilla LH, Garrett L, Adya N, Orlic D, Dutra A, Anderson S, et al. The fusion gene Cbfb-MYH11 blocks myeloid differentiation and predisposes mice to acute myelomonocytic leukaemia. Nature Genetics. 1999; 23: 144-146.

5. Higuchi M, O'Brien D, Kumaravelu P, Lenny N, Yeoh EJ, and Downing JR Expression of a conditional AML1-ETO oncogene bypasses embryonic lethality and establishes a murine model of human $t$ (8;21) acute myeloid leukemia. Cancer Cell. 2002; 1: 63-74.

6. Paschka P, Du J, Schlenk RF, Gaidzik VI, Bullinger L, Corbacioglu A, et al. Secondary genetic lesions in acute myeloid leukemia with inv (16) or (16;16): A study of the German-Austrian AML Study Group (AMLSG). Blood. 2013; 121: 170-177.

7. Care RS, Valk PJM, Goodeve AC, Abu-Duhier FM, Geertsma-Kleinekoort WMC, Wilson GA, et al. Incidence and prognosis of C-KIT and FLT3 mutations in core binding factor (CBF) acute myeloid leukaemias. British Journal of Haematology. 2003; 121: 775-777.

8. Paschka P, Marcucci G, Ruppert AS, Mrózek K, Chen H, Kittles RA, et al. Adverse Prognostic Significance of KIT Mutations in Adult Acute Myeloid Leukemia With inv (16) and t (8;21): A Cancer and Leukemia Group B Study. Journal of Clinical Oncology. 2006; 24: 3904-3911.

9. O'Donnell MR, Abboud CN, Altman J, Appelbaum FR, Arber DA, Attar E, et al. NCCN Clinical Practice Guidelines Acute myeloid leukemia. Journal of National Comprehensive Cancer Netwerk. 2012; 10: 984-1021.

10. Craddock CF. Full-intensity and reduced-intensity allogeneic stem cell transplantation in AML. Bone Marrow Transplantation. 2008; 41: 415-423.

11. Savani BN, Mielke S, Reddy N, Goodman S, Jagasia M, Rezvani K Management of relapse after allo-SCT for AML and the role of second transplantation. Bone Marrow Transplantation. 2009; 44: 769-777.

12. Meijer E, Cornelissen J. Allogeneic stem cell transplantation in acute myeloid leukemia in first or subsequent remission: weighing prognostic markers predicting relapse and risk factors for non-relapse mortality. Seminars in Oncology. 2008; 35: 449-457.

13. Mortimer J, Blinder MA, Schulman S, Appelbaum FR, Buckner CD, Clift RA et al. Relapse of acute leukemia after marrow transplantation: Natural history and results of subsequent therapy. Journal of Clinical Oncology. 1989; 7 : 50-57
14. Au WY, Kwong YL, Lie AK, Ma SK, Liang R. Extra-medullary relapse of leukemia following allogeneic bone marrow transplantation. Hematological Oncology. 1999; 17: 45-52

15. Cunningham I. Extramedullary sites of leukemia relapse after transplant. Leukemia \& Lymphoma. 2006; 47: 1754-1767.

16. Lee $\mathrm{KH}$, Lee JH, Choi SJ, Kim S, Seol M, Lee YS, et al. Bone marrow vs. extramedullary relapse of acute leukemia after allogeneic hematopoietic cell transplantation: Risk factors and clinical course. Bone Marrow Transplantation. 2003; 32: 835-842

17. Koc $Y$, Miller KB, Schenkein DP, Daoust $P$, Spraque K, Berkman E. Extramedullary tumors of myeloid blasts in adults as a pattern of relapse following allogeneic bone marrow transplantation. Cancer. 1999; 85: 608615

18. Lee KH, Lee JH, Choi SJ, Lee JH, Kim S, Seol M, et al. Bone marrow vs. extramedullary relapse of acute leukemia after allogeneic hematopoietic cell transplantation: Risk factors and clinical course Bone Marrow Transplantation. 2003; 32: 835-842

19. Ruiz-Arguelles GJ, Gomez-Almaguer D, Vela-Ojeda J, Morales-Toquero A, David-Gomez-Rangel J, Garcia-Ruiz-Esparza MA, et al. Extramedullary leukemic relapses following hematopoietic stem cell transplantation with nonmyeloablative conditioning. International Journal of Hematology. 2005; 82: $262-265$.

20. Shimoni A, Rand A, Shem-Tov N, Zilbershatz E, Yerushalmi R, Nagler A Isolated Extra-Medullary Relapse of Acute Leukemia After Allogeneic StemCell Transplantation (SCT): Different Kinetics and Better Prognosis than Systemic Relapse. Blood. 2008; 112: 2148

21. Yoshihara S, Ikegame K, Kaida K, Taniguchi K, Kato R, Inoue T, et al. Incidence of extramedullary relapse after haploidentical SCT for advanced AML/myelodysplastic syndrome. Bone Marrow Transplantation. 2012; 47: 669-676.

22. Solh M, DeFor TE, Weisdorf DJ, Kaufman DS. Extramedullary relapse of acute myelogenous leukemia after allogeneic hematopoietic stem cell transplantation: Better prognosis than systemic relapse. Biology of Blood Marrow Transplantation. 2012; 18: 106-112.

23. Singhal S, Powles R, Kulkarni S, Treleaven J, Saso R, Mehta J. Long-term follow-up of relapsed acute leukemia treated with immunotherapy after allogeneic transplantation: The inseparability of graft-versus-host disease and graft-versus-leukemia, and the problem of extramedullary relapse. Leukemia \& Lymphoma. 1999; 32: 505-512.

24. Chong G, Byrnes G, Szer J, Grigg A, et al. Extramedullary relapse afte allogeneic bone marrow transplantation for haematological malignancy. Bone Marrow Transplantation. 2000; 26: 1011-1015.

25. Harris AC, Mageneau J, Braun T, Kitko CL, Choi SW, Ferrara JLM, et al. Extramedullary Relapse In Acute Leukemia Following Allogeneic Hematopoietic Stem Cell Transplantation: Incidence, Risk Factors And Outcomes. Biology of Blood and Marrow Transplantation. 2010; 16: 177-178.
Austin J Obstet Gynecol - Volume 5 Issue 5 - 2018 Submit your Manuscript | www.austinpublishinggroup.com Mensah-Glanowska et al. (C) All rights are reserved
Citation: Mensah-Glanowska P, Glanowski D, Sporek-Kunicka A, Kviatkouskaya K, Szostek M, PiątkowskaJakubas B, et al. Late Ovarian and Intestinal Extramedullary Relapse of Acute Myeloid Leukemia with Inv 16 after Allogeneic Hematopoietic Stem Cell Transplantation. Austin J Obstet Gynecol. 2018; 5(5): 1111. 